\title{
A survey of publications with chironomid content represented in bibliographic databases on the web
}

Martin Spies

SNSB - Zoologische Staatssammlung München (ZSM), Münchhausenstr. 21, 81247 München, Germany.

E-mail: spies@zi.biologie.uni-muenchen.de

\section{Introduction}

A year and a half have passed since the opening on the world wide web of the "Bibliography of the Chironomidae" (http://literature.vm.ntnu.no/Chironomidae/), and three years since Odwin Hoffrichter sadly had to stop the invaluable service to our community that has resulted in his enormous contributions to the CHIRONOMUS newsletter from No. 9 (1995) through No. 23 (2010).

On this occasion, here is a look - of general interest and relevance, I would hope - at how our special literature database has performed, on its own and compared to some standard tools commonly used in searches for scientific publications.

\section{Sources and procedures}

Three online databases were searched between the 9th and 12th of December 2013. Each basic search operation covered a single calendar year only; sum totals calculated for longer periods were checked by searching with corresponding year ranges, where the entry fields and search functions allowed this. Many data for 2013 have yet to be entered in the databases; thus, this year can be considered only as far as general trends.

The "Bibliography of the Chironomidae" (abbreviated ChirB below) was searched by entering the respective figure in the "Year" field. As quite many individual entries in that field include more than one year figure, e.g. '1971 (“1970”)', '1972/73', '1974-1975', affected yearly totals were reduced accordingly.

The "Web of KnowledgesM" (WoK; Thomson Reuters; http://thomsonreuters.com/web-of-knowledge/) was searched using "All Databases" and the search conditions 'Topic= $($ chironom* $)$ AND Title= $($ chironom* $)$ '. The WoK available to me via subscription by the Bavarian State Library (Munich) includes six databases: BIOSIS Citation Index ${ }^{\mathrm{SM}}$ (1926-present), BIOSIS Previews ${ }^{\circledR}$ (1926-present), Current Contents Connect ${ }^{\circledR}$ (1998-present), Journal Citation Reports ${ }^{\circledR}$, MEDLINE $^{\circledR}$ (1950-present), and Web of Science ${ }^{\circledR}$ (1995-present).

The Zoological Record (ZR; Thomson Reuters) was searched via ZSM subscription to the OvidSP platform (Wolters Kluwer; http://ovidsp.tx.ovid.com/sp-3.10.0b/ovidweb.cgi), performing a "Multi-Field Search" with chironom* as the search term in "All Fields". This database reports 1978 as its official starting date; it includes some earlier publications too, but not enough for quantitative comparisons.

\section{Results}

Figure 1 shows the annual numbers found in each database for the period from 1970 to 2012, and an average from ChirB (535 titles per year) over the 40-year period 1970-2009.

For 1978-2012, the sum total in ChirB was 18,658 titles, whereas ZR and WoK returned 8,176 and 5,198 hits, respectively.

Considering works published from 2010 to the present, the titles in ChirB totalled 424 only, whereas ZR and WoK yielded 838 and 677 hits, respectively.

\section{Discussion}

For every year from 1970 to 2009, searches in the ChirB found many more titles than in the ZR and WoK databases. Considerable differences between the specialist tool and the general ones were to be expected, but the very low proportions returned by both of the latter - often under $50 \%$ of ChirB values, in a number of years even less than a third - are surprising. In any case, it looks clear that searching for chironomid references in the ZR or WoK cannot substitute for consulting the ChirB. 


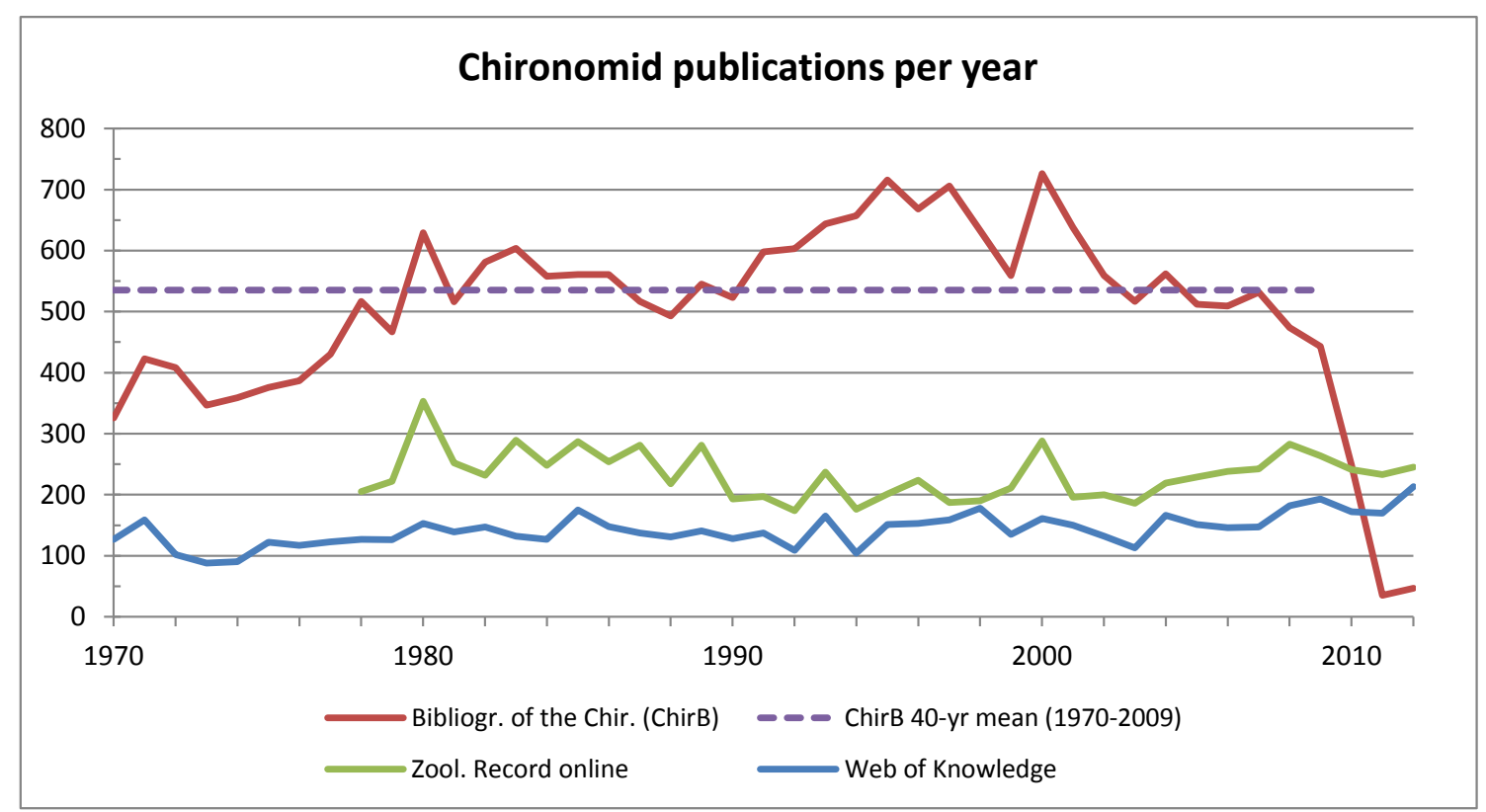

Figure 1. Annual numbers of publications with chironomid content found in three online bibliographic databases in December 2013.

The annual numbers registered by ZR and WoK vary relatively little throughout the period examined. In contrast, our bibliography indicates a strong and steady increase of the publication output from the 1970s through the 1990s, but shows a considerable reduction at the beginning of the $21^{\text {st }}$ century, and then a drastic drop after 2010. While the latter obviously coincides with the loss of Odwin's services, the earlier decrease after the year 2000 is unexplained at this time.

One would expect that each and everyone conducting or following Chironomidae research immediately combines the observations in the preceding two paragraphs and draws the obvious, inevitable and serious conclusion. If we do not find a feasible way to maintain and update the "Bibliography of the Chironomidae", anyone seeking to relate his studies to similar ones in the literature in a soundly scientific way will suffer dearly from the loss of the single most useful source of such references we have had available.

It is neither appropriate nor promising to hope for another colleague like Odwin Hoffrichter to come along and solve this problem for everyone else. However, there is a very simple and effective solution that is not impeded by any real obstacle or argument. Whenever any work with chironomid content that you have (co)authored has been published, just take a few minutes to enter the title in our freely accessible online database.

Actually, this little activity should be an integral part of publishing (making your findings known to a wider audience), thus is in your best interest as an author. The only evident factor standing in the way so far, and causing the catastrophic crash of the values marked by the red line in Figure 1, is laziness. The latter is a strong human feature - and I, too, have experience with it. However, you'll agree that it does not make a good enough reason, especially not for keeping you from making small contributions to a community that you wish to keep drawing large benefits from. 